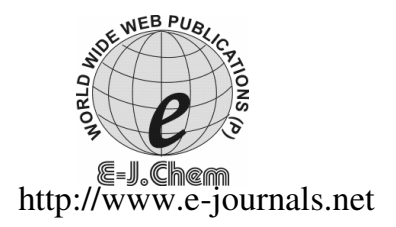

ISSN: 0973-4945; CODEN ECJHAO

E-Journal of Chemistry

2011, 8(3), 1438-1443

\title{
Investigation on Anticataract Activity of Triphala Ghrita
}

\author{
K. N. MAHAJAN ${ }^{\S}$, A.K.SINGHAI and G. P.VADNERE ${ }^{{ }^{*}}$ \\ ${ }^{\S}$ Smt.S.S.Patil College of Pharmacy, Chopda-425 127,(MS), India \\ Department of Pharmaceutical Sciences \\ Dr. H. S. Gour Vishwavidyalaya Sagar-470 003, (MP), India \\ gautamvadnere31@rediffmail.com
}

Received 7 June 2010; Accepted 27 August 2010

\begin{abstract}
Lab prepared Triphala ghrita was studied for its possible anticataract activity on galactose induced cataract in Swiss albino rats. Administration of Triphala ghrita at a dose of $216 \mathrm{mg} / 200 \mathrm{~g}, 1080 \mathrm{mg} / 200 \mathrm{~g}$, and $2160 \mathrm{mg} / 200 \mathrm{~g}$ of rat orally offered significant dose dependent protection against galactose induced cataract and delayed the onset and progression of cataract. It was seen that the dose of $1080 \mathrm{mg}$ of Triphala ghrita did not show stage II cataract in 14 days and stage III in 21 days. It did not show even stage III and stage IV cataract after 30 days whereas group B and group C showed stage III and stage IV cataracts. Dose of $2160 \mathrm{mg}$ did not showed stage IV cataract after 30 days but showed stage III cataract. Dose of $1080 \mathrm{mg}$ of Triphala ghrita offered significant protection against delaying the onset and progression of cataract in comparison to other doses. This effect may be attributed to the antioxidant activity of gallic acid, ellagic acid and ascorbic acid which shows their presence in Triphala ghrita. This preliminary study was encouraging but further studies are required to extrapolate the clinical usefulness of this formulation.
\end{abstract}

Keywords: Triphala ghrita, Anticataract, Antioxidant, Gallic acid, Ellagic acid.

\section{Introduction}

Cataract remains the leading cause of visual disability and blindness worldwide ${ }^{1}$. Apart from aging, various risk factors such as nutritional deficiencies or inadequacies, diabetes, sunlight, environmental factors, smoking and lack of consumption of antioxidants are known to increase the risk of cataract ${ }^{2,3}$. In recent years, a great emphasis has been laid on exploring the possibility of using natural resources to delay the onset and progression of cataract. Triphala ghrita is the most favourite formulation used by Ayurvedic scholars and practitioners in 
ancient time as either whole or separately with other drugs; locally as well as systematically ${ }^{4}$. Triphala ghrita contains Triphala (which consist of Emblica officinalis, Terminalia chebula and Terminalia belerica) and ghrita (cow ghee) having the various classical usefulness that includes Timira (cataract), Visarpa (erysipelas), Netra ruja (pain in eyes), Netra srava (lacrimation), Kandu (itching), Svayathu (oedaema), Visama jvara (intermittent fever), Sukla netra roga (eye disorders related to sclera), Vartma roga (disorders of eyelids). Oxidative damage to the constituents of the eye lens is considered to be a major mechanism in the development of cataract ${ }^{5,6}$. Triphala has been proved to be an antioxidant ${ }^{7,8}$. All its constituents are also proved to posses antioxidant activity like gallic $\operatorname{acid}^{9}$. Even ghrita (cow's ghee) consists of vitamin A and E which are the well established antioxidant. Thus, validating the traditional claim and possible potential of Triphala ghrita in prevention or delay of cataract using galactose induced cataract in Swiss albino rats was the main objective of this investigation.

\section{Experimental}

The quality raw materials required for the formulation of Triphala Ghrita were purchased from reputed Ayurvedic drug store at Jalgaon, Maharashtra, India. Further Triphala ghrita was prepared. Galactose, $1 \%$ Tropicamide purchased from Cadila (Le Sante), India.

\section{Animals}

Male and female Swiss albino rats weighing $200 \mathrm{~g}$ were housed in groups of five under standard laboratory conditions of temperature $\left(25 \pm 2{ }^{\circ} \mathrm{C}\right)$ and $12 / 12 \mathrm{~h} \mathrm{light/dark}$ cycle. Animals had free access to standard pellet diet and water ad libitum. Institutional Animal Ethical Committee has approved the protocol of the study.

\section{Administration of triphala ghrita}

The required dose for rat was calculated by using the standard dose calculation procedure from recommended clinical dose. Using intragastric catheterization through mouth each dose of triphala ghrita was administered respectively to each group of rat along with warm water, then $1 \mathrm{~mL}$ of rinsing was administered using distilled water.

\section{Statistical analysis}

The data were presented as mean \pm SEM. The statistical significance between the groups has been tested by ANOVA followed by Dunnett's test. A probability value less than 0.05 were considered as significant.

In vivo assessment of anticataract activity ${ }^{10,11}$

Swiss albino rats having an average body weight of $200 \mathrm{~g}$ were randomized in five groups, five animals in each group. Animals were fed for 30 days. By that time all the animals in group had developed mature cataract. Each group was fed a different diet as follows; Group A animals were fed a standard pellet diet; Group B animals were fed $30 \%$ galactose in the above diet. This was prepared by mixing 30 parts of galactose in 70 parts of powdered rat chow. Group C animals received the B-group diet and $216 \mathrm{mg}$ amount of Triphala ghrita along with distilled warm water; Group D animals received the B-group diet and $1080 \mathrm{mg}$ amount of Triphala ghrita along with warm distilled water; Group E animals received the B-group diet and $2160 \mathrm{mg}$ amount of Triphala ghrita along with warm distilled water $(n=5)$. 
Table 1. Effect of Triphala ghrita on the onset of galactose-induced cataract in rats observed after 7 days

\begin{tabular}{cccccc}
\hline & Group A & Group B & Group C & Group D & Group E \\
\hline Clear Stage & $100 \%$ & 0 & $10 \%$ & $25 \%$ & $30 \%$ \\
Stage I & 0 & $100 \%$ & $90 \%$ & $75 \%$ & $70 \%$ \\
Stage II & 0 & 0 & 0 & 0 & 0 \\
Stage III & 0 & 0 & 0 & 0 & 0 \\
Stage IV & 0 & 0 & 0 & 0 & 0 \\
\hline
\end{tabular}

Table 2. Effect of Triphala ghrita on the onset of galactose-induced cataract in rats observed after 14 days

\begin{tabular}{cccccc}
\hline & Group A & Group B & Group C & Group D & Group E \\
\hline Clear Stage & $100 \%$ & 0 & $5 \%$ & $25 \%$ & $15 \%$ \\
Stage I & 0 & 0 & $85 \%$ & $75 \%$ & $70 \%$ \\
Stage II & 0 & $100 \%$ & $10 \%$ & 0 & $15 \%$ \\
Stage III & 0 & 0 & 0 & 0 & 0 \\
Stage IV & 0 & 0 & 0 & 0 & 0 \\
\hline
\end{tabular}

Table 3. Effect of Triphala ghrita on the onset of galactose- induced cataract in rats observed after 21 days

\begin{tabular}{cccccc}
\hline & Group A & Group B & Group C & Group D & Group E \\
\hline Clear Stage & $100 \%$ & 0 & 0 & $15 \%$ & $10 \%$ \\
Stage I & 0 & 0 & $50 \%$ & $75 \%$ & $50 \%$ \\
Stage II & 0 & $10 \%$ & $30 \%$ & $10 \%$ & $30 \%$ \\
Stage III & 0 & $90 \%$ & $20 \%$ & 0 & $10 \%$ \\
Stage IV & 0 & 0 & 0 & 0 & 0 \\
\hline
\end{tabular}

Table 4. Effect of Triphala ghrita on the onset of galactose- induced cataract in rats observed after 30 days

\begin{tabular}{cccccc}
\hline & Group A & Group B & Group C & Group D & Group E \\
\hline Clear Stage & $100 \%$ & 0 & 0 & $10 \%$ & $5 \%$ \\
Stage I & 0 & 0 & $20 \%$ & $60 \%$ & $25 \%$ \\
Stage II & 0 & 0 & $25 \%$ & $30 \%$ & $40 \%$ \\
Stage III & 0 & 0 & $30 \%$ & 0 & $30 \%$ \\
Stage IV & 0 & $100 \%$ & $25 \%$ & 0 & 0 \\
\hline
\end{tabular}

\section{Slit lamp examination and cataract classification}

Eyes were examined every other day using a slit lamp microscope. $1 \%$ Tropicamide was used to dilate the pupil size. Initiation and progression of lenticular opacity was graded in four stages ${ }^{13}$. Clear or stage 0- no vacuoles present. Stage I- vacuoles of less than one third of the lens radius which is observed in 7 days. Stage II- vacuoles located at the periphery of the lens occupying an area of between one-third and two-thirds of the radius from the periphery which is observed in 14 days. Stage III- vacuoles extending up to two-thirds of the radius from the periphery which is observed in 21 days. Stage IV- vacuoles cover the entire lens, which appears white to the naked eye which is observed in 30 days. The incidence of cataract appearance was expressed as the percentage of total lenses in each group. 


\section{Results and Discussion}

Results of slit lamp examination indicated that all of the animals fed on the galactose diet (group B) developed stage I cataract after one week (7 days). After two week (14 days) group B developed stage II cataract. After 21 days, $10 \%$ lenses developed stage II cataract, $90 \%$ lenses developed stage III cataract. Mature cataract was developed in $100 \%$ lenses of group B rats within 30 days. Feeding of $216 \mathrm{mg}$ dose of Triphala ghrita (group C) showed $10 \%$ lenses with clear stage, $90 \%$ developed stage I cataract after 1 week. After 14 days group C showed $5 \%$ lenses of clear stage, $85 \%$ were in stage I, $10 \%$ were in stage II. After 21 days, group C showed 50\% lenses in stage I, 30\% in stage II, 20\% in stage III and no lenses were clear. After 30 days, group C had developed $20 \%$ lenses in stage I, $25 \%$ lenses in stage II, $30 \%$ lenses showed stage III and $25 \%$ lenses developed mature cataracts. Feeding of Triphala ghrita at the dose of $1080 \mathrm{mg}$ (group D) delayed the onset of cataract since after one week $25 \%$ lenses were in clear stage and $75 \%$ were in stage I. After 14 days $75 \%$ lenses developed stage I cataract but 25\% lenses were still clear. After 21 days also 15\% lenses were clear whereas in other groups no lens were in clear stage. $75 \%$ lenses were in stage I, $10 \%$ lenses were in stage II and no lenses showed stage III cataract which was seen in other groups. After 30 days 10\% were still in clear stage, $60 \%$ were in stage I and $30 \%$ were in stage II. No lenses showed stage III cataract and no lenses developed the mature stage which was observed in group B and group C. Dose of $2160 \mathrm{mg}$ of triphala ghrita also delayed the onset of cataract as 30\% lenses after 7 days showed clear stage, $70 \%$ lenses showed stage I cataract. After 14 days group E showed $15 \%$ of clear lenses, $70 \%$ lenses were in stage I and $15 \%$ were in stage II. After 21 days $10 \%$ lenses were in clear stage, $50 \%$ lenses showed stage I cataract, $30 \%$ lenses showed stage II cataract and $10 \%$ lenses were in stage III. After 30 days 5\% lenses were still in clear stage, $25 \%$ lenses showed stage I, $40 \%$ lenses showed stage II, $30 \%$ lenses showed stage III cataract. No lenses in group E also developed mature cataract. Group A animals were clear during the entire experimental period. The present study revealed that administration of Triphala ghrita at a dose of $216 \mathrm{mg}, 1080 \mathrm{mg}$, and 2160 $\mathrm{mg} / 200 \mathrm{~g}$ of rat orally offered significant dose dependent protection against galactose induced cataract in rats and delayed the onset and progression of cataract. It was seen that the dose of $1080 \mathrm{mg}$ of Triphala ghrita did not show stage II cataract in 14 days and stage III in 21 days. It did not even show stage III and stage IV cataract after 30 days whereas group B and group C showed stage III and stage IV cataracts. Dose of $2160 \mathrm{mg}$ did not show stage IV cataract after 30 days but showed stage III cataract. Dose $1080 \mathrm{mg}$ of Triphala ghrita which offers significant protection against cataract in comparison to other doses and it may be due to the presence of antioxidant constituents in Triphala ghrita.

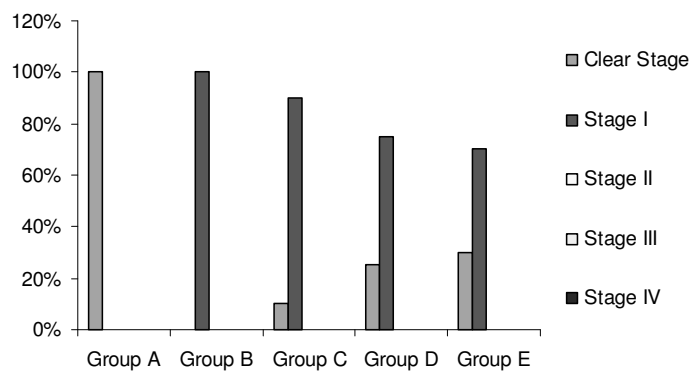

Figure 1. Graphical representation of effect of Triphala ghrita on galactose- induced cataract in rats after 7 days of the experiment 


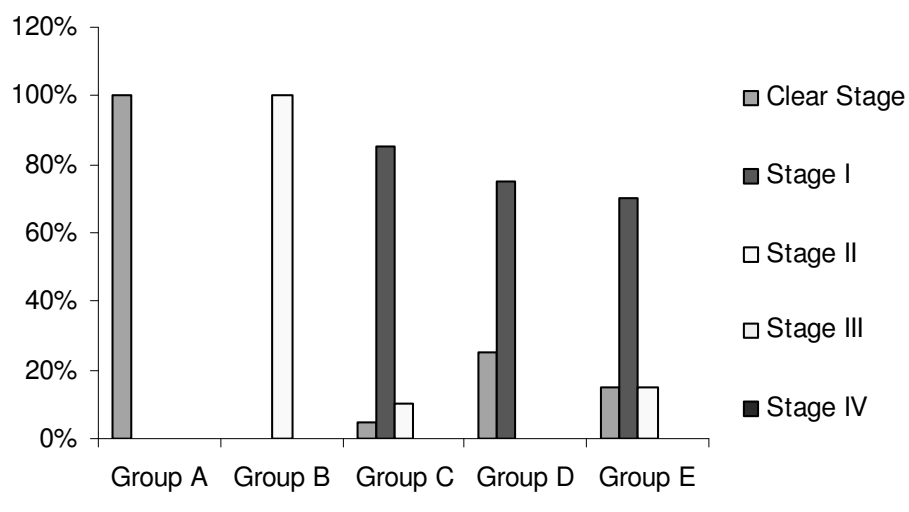

Figure 2. Graphical representation of effect of Triphala ghrita on galactose- induced cataract in rats after 14 days of the experiment

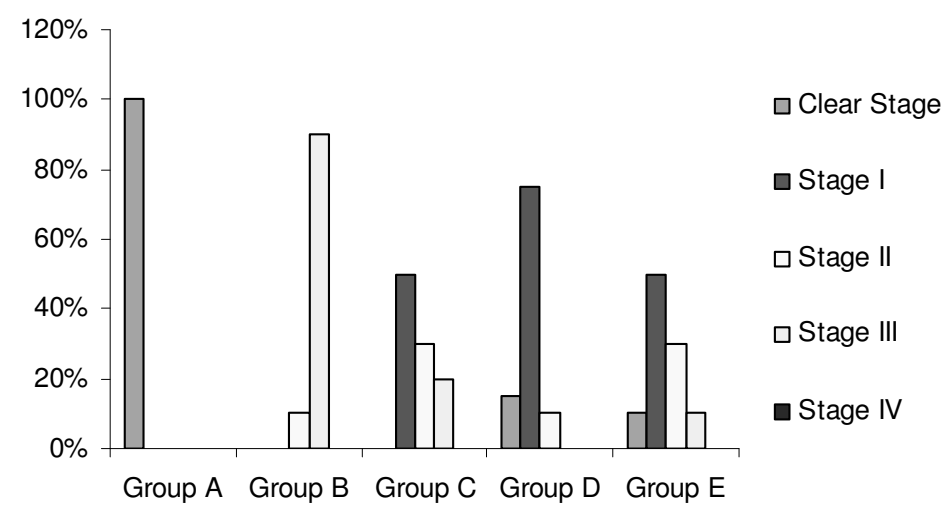

Figure 3. Graphical representation of effect of Triphala ghrita on galactose- induced cataract in rats after 21 days of the experiment

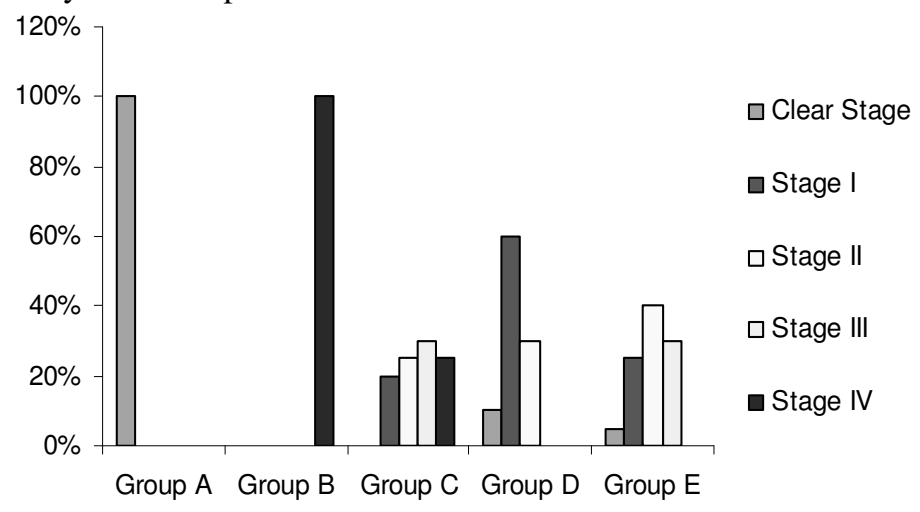

Figure 4. Graphical representation of effect of Triphala ghrita on galactose- induced cataract in rats after 30 days of the experiment 


\section{References}

1. Gupta S K, Joshi S, Tandon R and Mathur P, Indian J Ophthalmol., 1997, 45(4), 221-225.

2. Harding J J, Cataract: Biochemistry, Epidemiology and Pharmacology; $1^{\text {st }}$ Ed.; Chapman \& Hall: London,1991, 83-124.

3. Ughade S N, Zodpey S P and Khanolkar VA, Indian J Ophthalmol., 1998, 46(4), 221-227.

4. Tillotson A, Khalsa K and Caldecott T, Canadian Journal of Herbalism, 2001, 22, 216-44

5. Spector A, The lens and Oxidative Stress, In: Seis H, Ed., Oxidative Stress: Oxidants and Antioxidants; Academic Press: London, 1991, 529-58.

6. Varma S D, Devamanoharan P S and Morris S M, Crit Rev Food Sci Nutr., 1995, 35(1-2), 111-29.

7. Sabu M C and Kuttan R, J Ethnopharmacology, 2002, 81(2), 155-160.

8. Naik G H, Priyadarsini K I, Bhagirathi R G, Mishra B, Mishra K P, Banavalikar M M and Mohan H, Phytother Res., 2005, 19(7), 582-600.

9. Dhalwal K, Biradar Y.S, Shinde V.M, Mahadik K. R and Rajani M, Pharmacognosy Magazine, 2008, 4(14), 89-95.

10. Suryanarayana P, Krishnaswamy K and Reddy G B, Mol Vis., 2003, 9, 223-230.

11. Agrawal S S and Paridhavi M, Herbal drug Technology. Universities Press (India) Private Limited: Hyderabad, 2007, 561-567. 


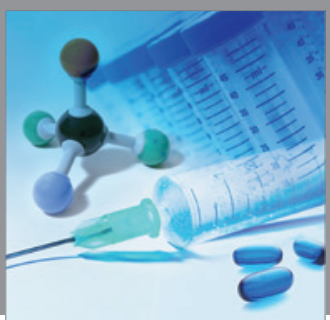

International Journal of

Medicinal Chemistry

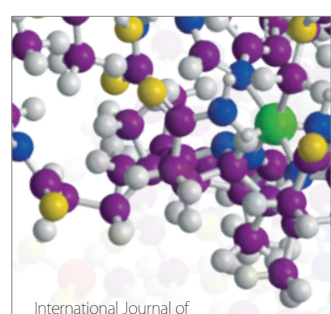

Carbohydrate Chemistry

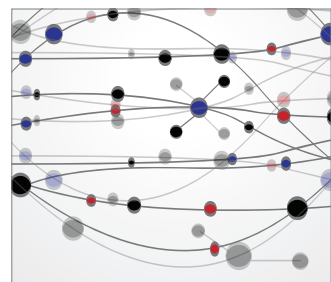

The Scientific World Journal
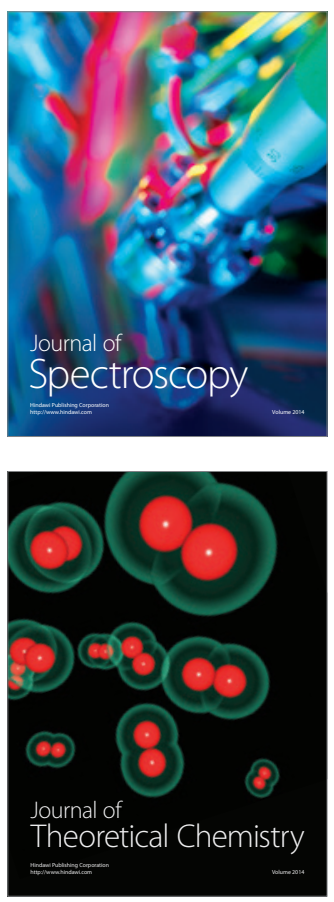
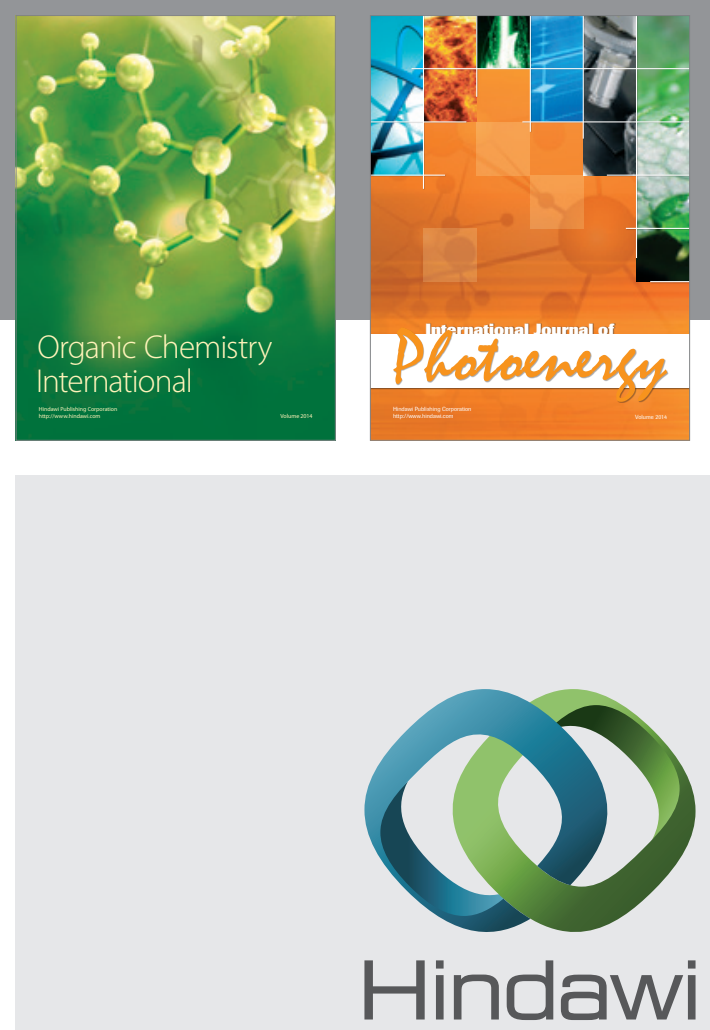

Submit your manuscripts at

http://www.hindawi.com
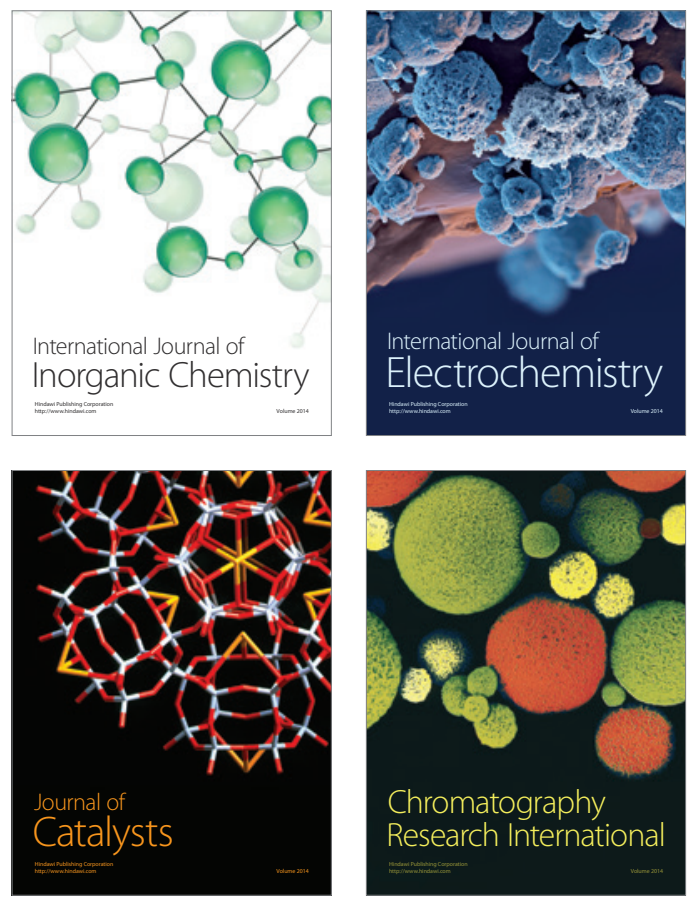
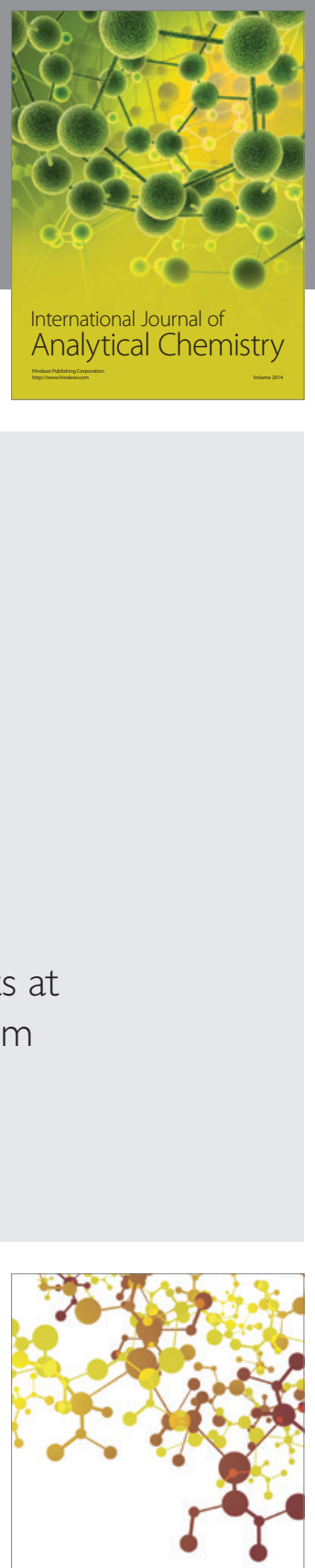

Journal of

Applied Chemistry
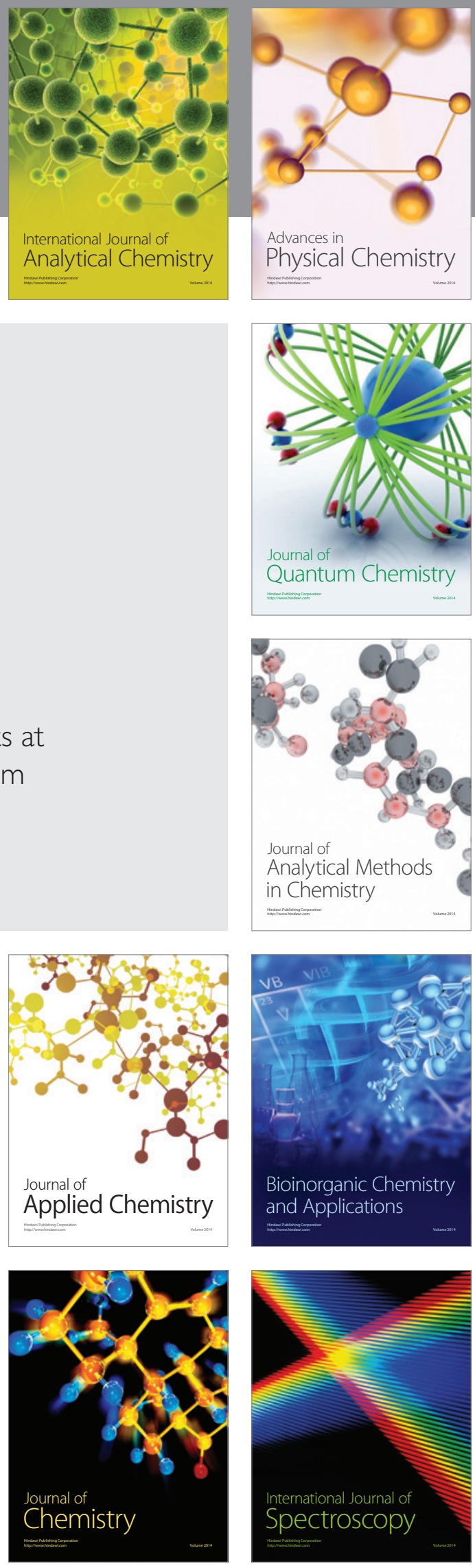